Research Paper

\title{
$\left[{ }^{[8}\right.$ F]FEBMP: Positron Emission Tomography Imaging of TSPO in a Model of Neuroinflammation in Rats, and in vitro Autoradiograms of the Human Brain
}

\author{
Anjani K. Tiwari*, ${ }^{*}, 2$, Bin Ji ${ }^{*}, 1$, Joji Yui ${ }^{1}$, Masayuki Fujinaga ${ }^{1}$, Tomoteru Yamasaki ${ }^{1}$, Lin Xie ${ }^{1}$, Rui Luo ${ }^{3}$, Yoko \\ Shimoda ${ }^{1}$, Katsushi Kumata ${ }^{1}$, Yiding Zhang ${ }^{1}$, Akiko Hatori ${ }^{1}$, Jun Maeda ${ }^{1}$, Makoto Higuchi' ${ }^{1}$, Feng Wang, ${ }^{3}, \bigotimes$ \\ and Ming-Rong Zhang, ${ }^{1}$ - \\ 1. Molecular Imaging Centre, National Institute of Radiological Sciences, Chiba, Japan \\ 2. Division of Cyclotron and Radiopharmaceutical Sciences, Institute of Nuclear Medicine and Allied Sciences, Delhi, India \\ 3. Department of Nuclear Medicine, Nanjing Hospital, Affiliated to Nanjing Medical University, Nanjing, China.
}

*These authors contributed equally to this work

$\triangle$ Corresponding author: Ming-Rong Zhang, PhD., Molecular Probe Program, Molecular Imaging Centre, National Institute of Radiological Sciences, 4-9-1 Anagawa, Inage-ku, Chiba 263-8555, Japan. Phone: 81-43-382-3709; Fax: 81-43-206-3261; E-mail: zhang@nirs.go.jp. Feng Wang, PhD., Department of Nuclear Medicine, Nanjing Hospital, Affiliated to Nanjing Medical University, 68 Chanle Road, Nanjing 210006, China. Phone: 86-25-52271456. E-mail: fengwangcn@hotmail.com

(C) 2015 Ivyspring International Publisher. Reproduction is permitted for personal, noncommercial use, provided that the article is in whole, unmodified, and properly cited. See http://ivyspring.com/terms for terms and conditions.

Received: 2015.03.03; Accepted: 2015.05.09; Published: 2015.05.26

\begin{abstract}
We evaluated the efficacy of 2-[5-(4-[ $\left.{ }^{18} \mathrm{~F}\right]$ fluoroethoxy-2-oxo-1,3-benzoxazol-3(2H)-yl)$\mathrm{N}$-methyl-N-phenylacetamide] ([ $\left.\left.{ }^{18} \mathrm{~F}\right] \mathrm{FEBMP}\right)$ for positron emission tomography (PET) imaging of translocator protein (18 kDa, TSPO). Dissection was used to determine the distribution of $\left[{ }^{18} \mathrm{~F}\right] \mathrm{FEBMP}$ in mice, while small-animal PET and metabolite analysis were used for a rat model of focal cerebral ischemia. $\left[{ }^{18} \mathrm{~F}\right] \mathrm{FEBMP}$ showed high radioactivity uptake in mouse peripheral organs enriched with TSPO, and relatively high initial brain uptake $(2.67 \pm 0.12 \% \mathrm{ID} / \mathrm{g})$. PET imaging revealed an increased accumulation of radioactivity in the infarcted striatum, with a maximum ratio of $3.20 \pm 0.12$, compared to non-injured striatum. Displacement with specific TSPO ligands lowered the accumulation levels in infarcts to those on the contralateral side. This suggests that the increased accumulation reflected TPSO-specific binding of $\left[{ }^{18} \mathrm{~F}\right] \mathrm{FEBMP}$ in vivo. Using a simplified reference tissue model, the binding potential on the infarcted area was $2.72 \pm 0.27$. Metabolite analysis in brain tissues showed that $83.2 \pm 7.4 \%$ and $76.4 \pm 2.1 \%$ of radioactivity was from intact $\left[{ }^{18} \mathrm{~F}\right] \mathrm{FEBMP}$ at 30 and $60 \mathrm{~min}$, respectively, and that this ratio was higher than in plasma $(8.6 \pm 1.9 \%$ and $3.9 \pm 1.1 \%$, respectively). In vitro autoradiography on postmortem human brains showed that TSPO rs6971 polymorphism did not affect binding sites for $\left[{ }^{18} \mathrm{~F}\right] \mathrm{FEBMP}$. These findings suggest that $\left[{ }^{18} \mathrm{~F}\right] \mathrm{FEBMP}$ is a promising new tool for visualization of neuroinflammation.
\end{abstract}

Key words: [18F]FEBMP; translocator protein (18 kDa); neuroinflammation; binding potential; rs6971 polymorphism

\section{Introduction}

Neuroinflammation characterized by the activation of glial cells is an important pathological process that is involved in the progression of many neurodegenerative disorders. Since the expression of translocator protein $(18 \mathrm{kDa}, \mathrm{TSPO})$ is greatly induced in activated glial cells, quantitative assessment of TSPO with positron emission tomography (PET) is a powerful tool to evaluate neuroinflammation [1-3]. 
[11C]PK11195 was the first TSPO radioligand to be developed and evaluated [4]. While full quantification of $(R)\left[{ }^{11} \mathrm{C}\right] \mathrm{PK} 11195$ has been performed, the results were noisy because of a low signal-to-noise ratio, which was likely due to relatively high levels of non-specific binding [5-8]. Because PET imaging is a powerful technique for translational research, many research groups are actively engaged in searching for new TSPO ligands with improved properties $[9,10]$. A few of the ligands discovered thus far, including [11C]DAA1106 [11, 12], [ ${ }^{18}$ F]FEDAA1106 [13, 14], [11C]PBR28 [15], [11C]AC-5216 [16], [18F]DPA714 [17], and $\left[{ }^{18} \mathrm{~F}\right]$ PBR111 [18], have been developed for preclinical and clinical study. Although these second-generation TSPO radioligands have improved signal-to-noise ratios, they show substantial heterogeneity in their binding potentials due to intersubject variability $[8,19]$. A rs6971 polymorphism in the gene that encodes TSPO is fully responsible for such difference in affinity. This polymorphism leads to an amino acid substitution, from alanine to threonine (Ala147Thr), and therefore leads to three distinct binding affinity classes; high-affinity binder (HAB, Ala/Ala amino acid in 147 position of TSPO protein, major genotype) and low-affinity binder (LAB, $\mathrm{Thr} / \mathrm{Thr}$, minor genotype) express a single binding site for TSPO with either high or low affinity, respectively, whereas the mixed-affinity binder (MAB, Ala/Thr amino acid) expresses both binding sites [20, 21].

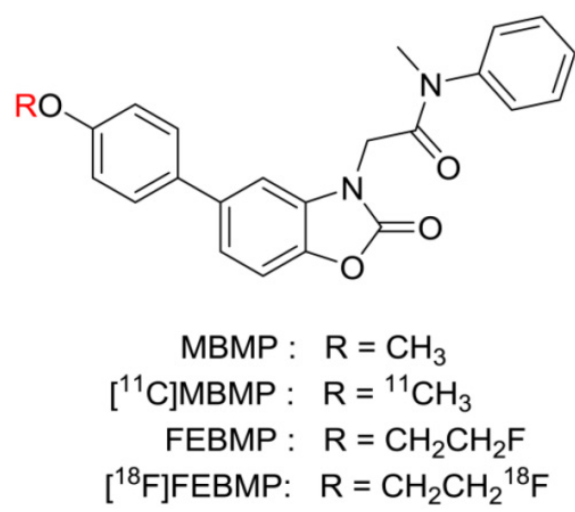

Figure 1. Chemical structure of novel TSPO ligands

Therefore, new TSPO ligand candidates with different structural skeletons that are not sensitive to this polymorphism are desirable. Recently, we developed 2-[5-(4-[11C]methoxyphenyl)-2-oxo-1,3benzoxazol-3(2H)-yl]-N-methyl-N-phenylacetamide ([11C]MBMP, Fig. 1) as a potent and selective PET ligand for TSPO [22]. An in vivo PET study demonstrated high specific binding and a higher binding potential of $\left[{ }^{11} \mathrm{C}\right] \mathrm{MBMP}$ than $(R)\left[{ }^{11} \mathrm{C}\right] \mathrm{PK} 11195$ toward
TSPO in the ischemic rat brain. Because ${ }^{18} \mathrm{~F}$ has a longer half-life than ${ }^{11} \mathrm{C}$, we altered the methoxy group using a fluoroethoxy group to derive 2-[5-(4-fluoroethoxy-2-oxo-1,3-benzoxazol-3(2H)-yl)$N$-methyl- $N$-phenylacetamide (FEBMP, Fig. 1). Importantly, this replacement did not change the binding affinity (Ki) of the molecule for TSPO in a decisive way (MBMP vs FEBMP: $3.9 \pm 0.6 \mathrm{nM}$ vs. $6.6 \pm 0.7 \mathrm{nM}$ ) [23].

In this study, we evaluated the efficacy of 2-[5-(4-[18F]fluoroethoxy-2-oxo -1,3-benzoxazol-3(2H)yl)- $N$-methyl- $N$-phenylacetamide ([18F]FEBMP, Fig. 1$)$ for PET imaging of TSPO in ischemic rat brains. We also determined the influence of the TSPO rs6971 polymorphism on the binding affinity of $\left[{ }^{18} \mathrm{~F}\right]$ FEBMP using in vitro autoradiographic analyses in postmortem human brains.

\section{Materials and methods}

\section{Chemicals and instrumentation}

All chemicals were purchased from commercial sources. High performance liquid chromatography (HPLC) separation and analysis were performed using a JASCO HPLC system (JASCO, Tokyo, Japan). Unlabelled MBMP and FEBMP were synthesized in house, and ${ }^{18} \mathrm{~F}$ and ${ }^{11} \mathrm{C}$ were produced using a CYPRIS HM-18 cyclotron (Sumitomo Heavy Industry, Tokyo, Japan). Effluent radioactivity was monitored using a $\mathrm{NaI}(\mathrm{Tl})$ scintillation detector system. If not otherwise stated, radioactivity was measured with an IGC-3R Curiemeter (Aloka, Tokyo, Japan).

\section{Production of $\left[{ }^{18} \mathrm{~F}\right]$ FEBMP}

$\left[{ }^{18} \mathrm{~F}\right]$ FEBMP was synthesized by reacting a desmethyl precursor with [ $\left.{ }^{18} \mathrm{~F}\right]$ fluoroethyl bromide in the presence of $\mathrm{NaOH}$ at $120^{\circ} \mathrm{C}$ for $10 \mathrm{~min}$. HPLC separation for the reaction mixture gave $\left[{ }^{18} \mathrm{~F}\right] \mathrm{FEBMP}$ in $22 \pm 4 \%(n=15)$ radiochemical yields, based on $\left[{ }^{18} \mathrm{~F}\right] \mathrm{F}^{-}$corrected for physical decay at the synthesis times of $64 \pm 5 \mathrm{~min}$ from the end of bombardment. The radiochemical purity and specific activity of $\left[{ }^{18} \mathrm{~F}\right] \mathrm{FEBMP}$ was $\geq 98 \%$ and $90-350 \mathrm{GBq} / \mu \mathrm{mol}$ at the end of synthesis. These analytical results were in compliance with the quality control/assurance specifications of radiopharmaceuticals that are produced in our facility.

\section{Production of $11 \mathrm{C}$-labelled ligands}

$(R)\left[{ }^{11} \mathrm{C}\right] \mathrm{PK} 11195,\left[{ }^{11} \mathrm{C}\right] \mathrm{PBR} 28,\left[{ }^{11} \mathrm{C}\right] \mathrm{DAA} 1106$ and $\left[{ }^{11} \mathrm{C}\right] \mathrm{AC}-5216$ were prepared by reacting their corresponding desmethyl precursors with $\left[{ }^{11} \mathrm{C}\right]$ methyl iodide according to methods reported previously $[4,11$, $16,24]$. The radiochemical purity and specific activity of these radioligands were $\geq 98 \%$ and in the range of $40-90 \mathrm{GBq} / \mu \mathrm{mol}$, respectively, at the end of synthe- 
sis.

\section{Animals}

All animals were maintained and handled in accordance with the recommendations of the National Institute of Health and institutional guidelines of the National Institute of Radiological Sciences (NIRS). Experiments conducted in the NIRS were approved by the Animal Ethics Committee. Male ddY mice (8 weeks old, 34-36 g) and Sprague-Dawley (SD) rats (male, 8-9 weeks old, 240-330 g) were purchased from Japan SLC (Shizuoka, Japan). The animals were housed under a 12/12-h dark/light cycle under optimal conditions.

\section{Biodistribution study}

The ddY mice were injected with $\left[{ }^{18} \mathrm{~F}\right] \mathrm{FEBMP}$ $(1.85 \mathrm{MBq}, 10 \mathrm{pmol})$ through the tail vein, and were sacrificed at six time intervals $(1,5,15,30,60$, and 90 min). Blood samples were collected from each group $(n=4)$ and the brain, heart, kidneys, liver, lungs, spleen, small intestine, testis, muscles, and bones (thighbone) were quickly removed and weighed. The level of radioactivity in each tissue was measured by a 1480 Wizard 3" autogamma counter (Perkin Elmer, Waltham, MA, USA) and expressed as percentage of the injected dose per gram of wet tissue (\% ID/g). The correction for decay was taken into account during the radioactivity measurements.

\section{Ischemic model}

Mild focal ischemia was produced by intraluminal occlusion of the middle cerebral artery for 30 min using an intraluminal thread model, as mentioned in our previous works [25]. In general, SD rats were anesthetized with $4 \%(\mathrm{v} / \mathrm{v})$ isoflurane and maintained under anaesthesia with $1.8 \%$ isoflurane. A 4.0-monofilament nylon suture coated with silicon was inserted into the internal carotid artery up to the level of the middle cerebral artery branches (approximately 16-18 $\mathrm{mm}$ from the internal carotid artery), and the neck incision was closed with a silk suture. Thirty min after regaining consciousness from anaesthesia, rats were again anesthetized and the filament was carefully removed for reperfusion. Body temperature was monitored and maintained at optimal levels throughout the surgery. The rats were then used for PET imaging or metabolite analysis at 7 days post ischemic surgery.

\section{PET study and imaging analysis}

The PET study was performed using a small-animal PET scanner (Siemens Medical Solutions USA, Knoxville, TN, USA), which provides 159 transaxial slices $0.796 \mathrm{~mm}$ (center-to-center) apart, a $10 \mathrm{~cm}$ transaxial field of view (FOV), and a $12.7 \mathrm{~cm}$ axial FOV for imaging. Rats were anesthetized with $1.5 \%(\mathrm{v} / \mathrm{v})$ isoflurane during the scan, and their body temperatures were maintained with a $40^{\circ} \mathrm{C}$ water circulation system (T/Pump TP401, Gaymar Industries, NY, USA). [ ${ }^{18}$ F]FEBMP (16-18 MBq, 0.07-0.15 nmol) was intravenously injected via tail vein, and a 90-min list-mode emission scan was carried out immediately. The time frame reconstruction was as follows: 1 min $\times 4$ frames, 2 min $\times 8$ frames, and $5 \min \times$ 14 frames. For the displacement experiments, unlabelled MBMP (1 mg/ $\mathrm{kg}$ ) or PK11195 (3 mg/kg), solved in $300 \mu \mathrm{L}$ of saline containing $15 \%$ ethanol and $10 \%$ Tween 80, was injected 20 min after PET scans with $\left[{ }^{18} \mathrm{~F}\right]$ FEBMP were started. Three independent experiments were performed for each group.

Data modelling for PET scans was performed using three-dimensional sinograms, which were changed into two-dimensional sinograms by Fourier rebinning. Dynamic image reconstruction was done by filtered back-projection using Hanning's filter with a Nyquist cut-off frequency of 0.5 cycles/pixel. PET images were analyzed using ASIPro VM ${ }^{\mathrm{TM}}$ (Analysis Tools and System Setup/Diagnostics Tool, Siemens Medical Solutions) with reference to a high-resolution magnetic resonance imaging (MRI) template, which was generated as described in our previous publication [26]. The regions of interest (ROIs) were manually placed on ipsilateral and contralateral sides of the striatum with reference to the MRI template.

The nondisplacable binding potential $\left(\mathrm{BP} P_{\mathrm{ND}}\right)$ on the ipsilateral side of the striatum was calculated with a simplified reference tissue model (SRTM) [27] using the contralateral side as the reference region. The model analysis was performed by PMOD version 3.4 image analysis software (PMOD Technologies, Zurich, Switzerland).

\section{Statistical analyses}

Statistical analyses were performed using Microsoft Office Excel 2007 and SPSS software. All data are expressed as the mean \pm SEM. PET data were analyzed by one-way repeated-measures analysis of variance (ANOVA). In the analyses, $p$ values of $<0.05$ were considered statistically significant.

\section{Radiolabelled metabolite analysis in ischemic rats}

The metabolite analysis was done in separate animals. $\left.{ }^{18} \mathrm{~F}\right] \mathrm{FEBMP}(10 \mathrm{MBq}, 0.07 \mathrm{nmol})$ solutions were injected intravenously into the ischemic rat model through the tail vein, and these animals were sacrificed by cervical dislocation at two time points, 30 and $60 \mathrm{~min}$ ( $n=3$ for each point). Whole brains and 0.8-1.0 mL of blood samples were collected and analyzed as per our previous work [22]. The conditions 
for HPLC analyses were as follows: Capcell Pak $\mathrm{UG} 80 \mathrm{C}_{18}$ column, $4.6 \mathrm{~mm}$ internal diameter $\times 250 \mathrm{~mm}$ length; $\mathrm{MeCN} / \mathrm{H}_{2} \mathrm{O} / \mathrm{Et}_{3} \mathrm{~N}, 7 / 3 / 0.01(\mathrm{v} / \mathrm{v} / \mathrm{v})$; and flow rate, $1.0 \mathrm{~mL} / \mathrm{min}$. In parallel, radioactivity fractions in the HPLC waste solution were also measured by using an autogamma counter.

\section{In vitro autoradiography of the human brain}

Postmortem human brains for in vitro autoradiographic analysis and related genotypical information were obtained from the Center for Neurodegenerative Disease Research at the University of Pennsylvania Perelman School of Medicine. Two HABs (Ala/Ala in 147 position of TSPO protein) and two LABs (Thr/Thr) from healthy controls were used in the present study, and two of these human brains, LAB-1 and HAB-1, were used for a correlation analysis.

The brains were cut into $20-\mu \mathrm{m}$-thick sections and stored at $-80^{\circ} \mathrm{C}$ until they were used. The brain sections were preincubated with Tris- $\mathrm{HCl}$ buffer for $30 \mathrm{~min}$, followed by incubation with either of the following radiolabelled ligands: $\left.{ }^{18} \mathrm{~F}\right] \mathrm{FEBMP}(0.5 \mathrm{nM})$, $(R)\left[{ }^{11} \mathrm{C}\right]$ PK11195 $(0.5 \mathrm{nM}),\left[{ }^{11} \mathrm{C}\right]$ PBR28 $(0.5 \mathrm{nM})$, $\left[{ }^{11} \mathrm{C}\right] A C-5216(0.5 \mathrm{nM})$, or [ $\left.{ }^{11} \mathrm{C}\right] \mathrm{DAA} 1106(0.5 \mathrm{nM})$. Because higher incubation concentration than $\mathrm{K}_{\mathrm{d}}$ or $\mathrm{K}_{\mathrm{i}}$ for target might affect quantitative linearity and too low concentration would cause noise in image, the present concentration was designed at $0.5 \mathrm{nM}$ and was consider as the achievable concentration (usually less than $2 \mathrm{nM}$ ) of these ligands in the living brain. These radioligands were added in $50 \mathrm{mM}$ Tris- $\mathrm{HCl}$ buffer containing $5 \%$ ethanol, and incubation of the brain sections occurred at room temperature for $1 \mathrm{~h}$. To determine specific binding of these radioligands for TSPO, unlabeled PK11195 $(10 \mu \mathrm{M})$ was added to incubation solution in advance. Sections were then rinsed twice for $2 \mathrm{~min}$ in ice-cold wash buffer (50 mM Tris-HCl buffer containing 5\% ethanol) and dipped into distilled water for $10 \mathrm{sec}$. The brain sections were dried with cold air and attached to an imaging plate (BAS-MS2025; GE Healthcare, Piscateway, NJ, USA) for optimized contact periods. Radioactivity was detected by scanning the imaging plate using a BAS-5000 system (FIUJIFILM, Tokyo, Japan). ROIs were carefully placed over the gray matter of the temporal cortex with the reference of naked-eye observation, and radioactivity was expressed as photo-stimulated luminescence (PSL) per unit area $\left(\mathrm{PSL} / \mathrm{mm}^{2}\right)$. In the present study, there were five normal post-mortem human brains available for controls. Two of them, LAB-1 and HAB-1, were used for a correlation analysis.

\section{Results}

\section{Biodistribution study}

Intravenous injection of $\left.{ }^{18} \mathrm{~F}\right] \mathrm{FEBMP}$ into normal mice resulted in high radioactivity accumulation in the lungs, heart, and kidneys with values from approximately 130 to $13 \% \mathrm{ID} / \mathrm{g}$. Medium concentrations of radioactivity accumulated in the small intestine, muscle, liver, spleen, and testis with values from approximately 0.6 to $4 \% \mathrm{ID} / \mathrm{g}$. The radioactivity concentration in plasma continuously decreased within $15 \mathrm{~min}$ of ligand injection and increased thereafter, possibly due to increased release of radioactive metabolite from liver or enterohepatic circulation. A relatively high initial uptake (approximately $2.7 \%$ ID/g) was observed in the mouse brain, the target tissue in this study, and the radioactivity level appeared to decrease to approximately $45 \%$ of the initial peak value within $90 \mathrm{~min}$. During the initial phase after ligand injection, relatively high radioactivity (approximately $3.8 \% \mathrm{ID} / \mathrm{g}$ ) was observed to accumulate in the thighbones, and these values appeared to slightly increase at a later phase of observation (Table $1)$.

Table 1. Biodistribution (\% ID/g) of $\left[{ }^{18} \mathrm{~F}\right] \mathrm{FEBMP}$ in mice

\begin{tabular}{ccccccc}
\hline \multicolumn{7}{c}{ Time after the injection $(\mathrm{min})$} \\
\hline Organ/tissue & 1 & 5 & 15 & \multicolumn{1}{c}{30} & \multicolumn{1}{c}{60} & \multicolumn{1}{c}{90} \\
Blood & $2.24 \pm 0.72$ & $1.06 \pm 0.11$ & $0.80 \pm 0.10$ & $0.87 \pm 0.16$ & $1.26 \pm 0.08$ & $1.41 \pm 0.11$ \\
Heart & $19.71 \pm 1.21$ & $18.20 \pm 1.58$ & $13.20 \pm 0.46$ & $10.81 \pm 1.42$ & $6.43 \pm 0.74$ & $4.76 \pm 0.32$ \\
$\quad$ Lung & $129.63 \pm 15.12$ & $56.58 \pm 2.53$ & $29.46 \pm 0.61$ & $24.73 \pm 5.86$ & $12.55 \pm 1.23$ & $9.45 \pm 0.96$ \\
Liver & $1.76 \pm 0.12$ & $3.39 \pm 0.16$ & $5.11 \pm 0.75$ & $4.22 \pm 0.58$ & $3.25 \pm 0.82$ & $2.47 \pm 0.21$ \\
& & & & & & \\
Spleen & $2.73 \pm 1.56$ & $9.18 \pm 0.81$ & $9.71 \pm 0.89$ & $10.71 \pm 0.96$ & $8.20 \pm 0.56$ & $6.78 \pm 0.83$ \\
Kidney & $12.64 \pm 2.16$ & $14.91 \pm 1.41$ & $16.16 \pm 0.80$ & $16.53 \pm 1.71$ & $15.58 \pm 1.16$ & $14.27 \pm 2.15$ \\
S. Intestine & $4.33 \pm 0.18$ & $4.87 \pm 0.26$ & $5.70 \pm 0.32$ & $5.79 \pm 0.74$ & $5.77 \pm 0.49$ & $5.34 \pm 0.53$ \\
& & & & & & \\
Testis & $0.61 \pm 0.08$ & $0.82 \pm 0.07$ & $0.96 \pm 0.06$ & $1.23 \pm 0.06$ & $1.50 \pm 0.05$ & $1.79 \pm 0.15$ \\
Muscle & $2.17 \pm 0.09$ & $2.84 \pm 0.63$ & $2.60 \pm 0.27$ & $2.27 \pm 0.49$ & $2.42 \pm 0.21$ & $2.34 \pm 0.40$ \\
Bone & $1.23 \pm 0.03$ & $1.89 \pm 0.52$ & $1.96 \pm 0.21$ & $1.93 \pm 0.06$ & $3.13 \pm 0.42$ & $3.80 \pm 0.16$ \\
Brain & $2.67 \pm 0.20$ & $1.89 \pm 0.06$ & $1.25 \pm 0.02$ & $1.11 \pm 0.08$ & $1.16 \pm 0.04$ & $1.15 \pm 0.09$ \\
\hline
\end{tabular}

Data are presented as Mean \pm SEM.

Four animals were used for each time point. 


\section{Small-animal PET studies}

PET images with [ $\left.{ }^{18} \mathrm{~F}\right] \mathrm{FEBMP}$ and time-activity curves (TACs) showed higher accumulation of radioactivity in the ipsilateral striatum of the rat model of transient focal ischemia compared to radioactivity that accumulated in the corresponding contralateral area. The maximum ipsilateral-to-contralateral ratio was $3.20 \pm 0.12$ at $60 \mathrm{~min}$ post-injection (Fig. 2).
Treatment with unlabelled MBMP or PK11195 led to an overt decrease in radioactivity on the ipsilateral side of the brain. Moreover, after 30 min of treatment, levels appeared to be similar to those contralateral to the infarct (Fig. 3). Using SRTM, with the contralateral side of the brain as reference tissue, the $\mathrm{BP}_{\mathrm{ND}}$ value for $\left[{ }^{18} \mathrm{~F}\right] \mathrm{FEBMP}$ on the ipsilateral side of the brain was $2.72 \pm 0.27$.
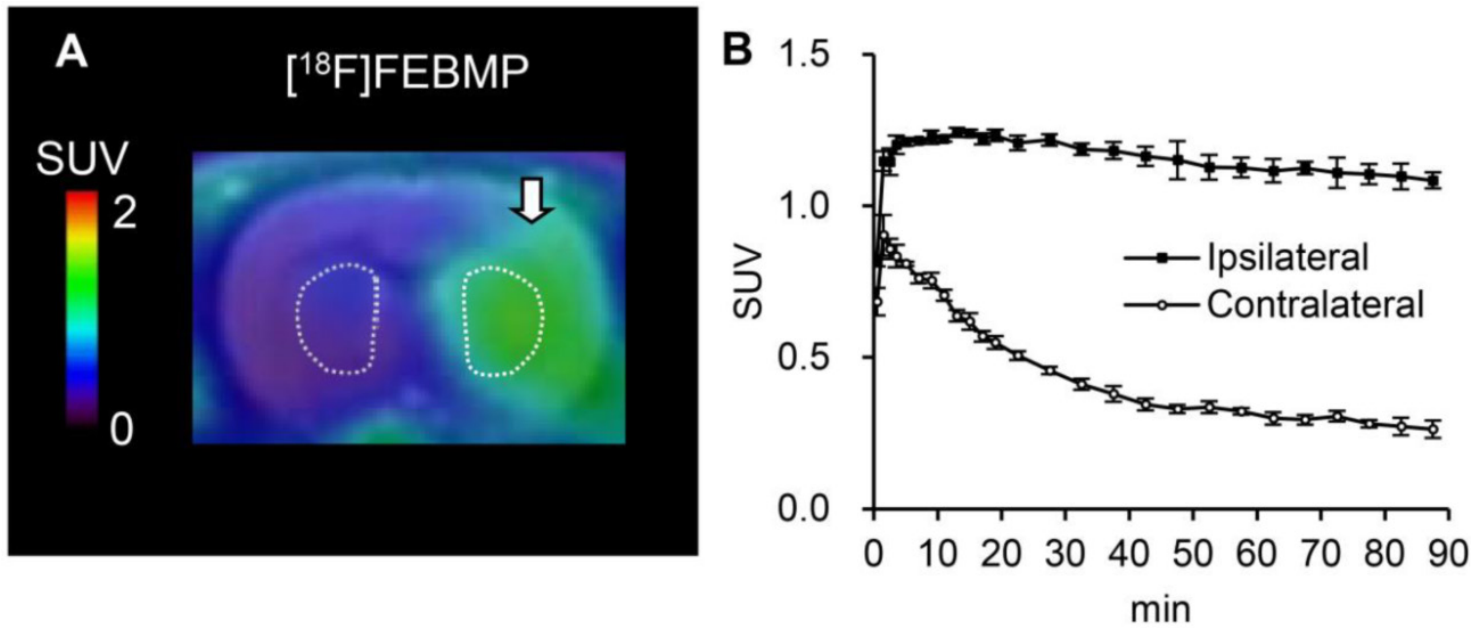

Figure 2. In vivo imaging with [18F]FEBMP in ischemic rat brains. A: Representative coronal PET image (summation of 0-90 min) was overlaid on the MRI template of a rat brain. The arrow indicates the ischemic areas. B: Time-activity curve for the ipsilateral and contralateral striatum. Data (mean \pm SEM, $n=3)$ were from three ischemic rat brains. SUV, standardized uptake value.
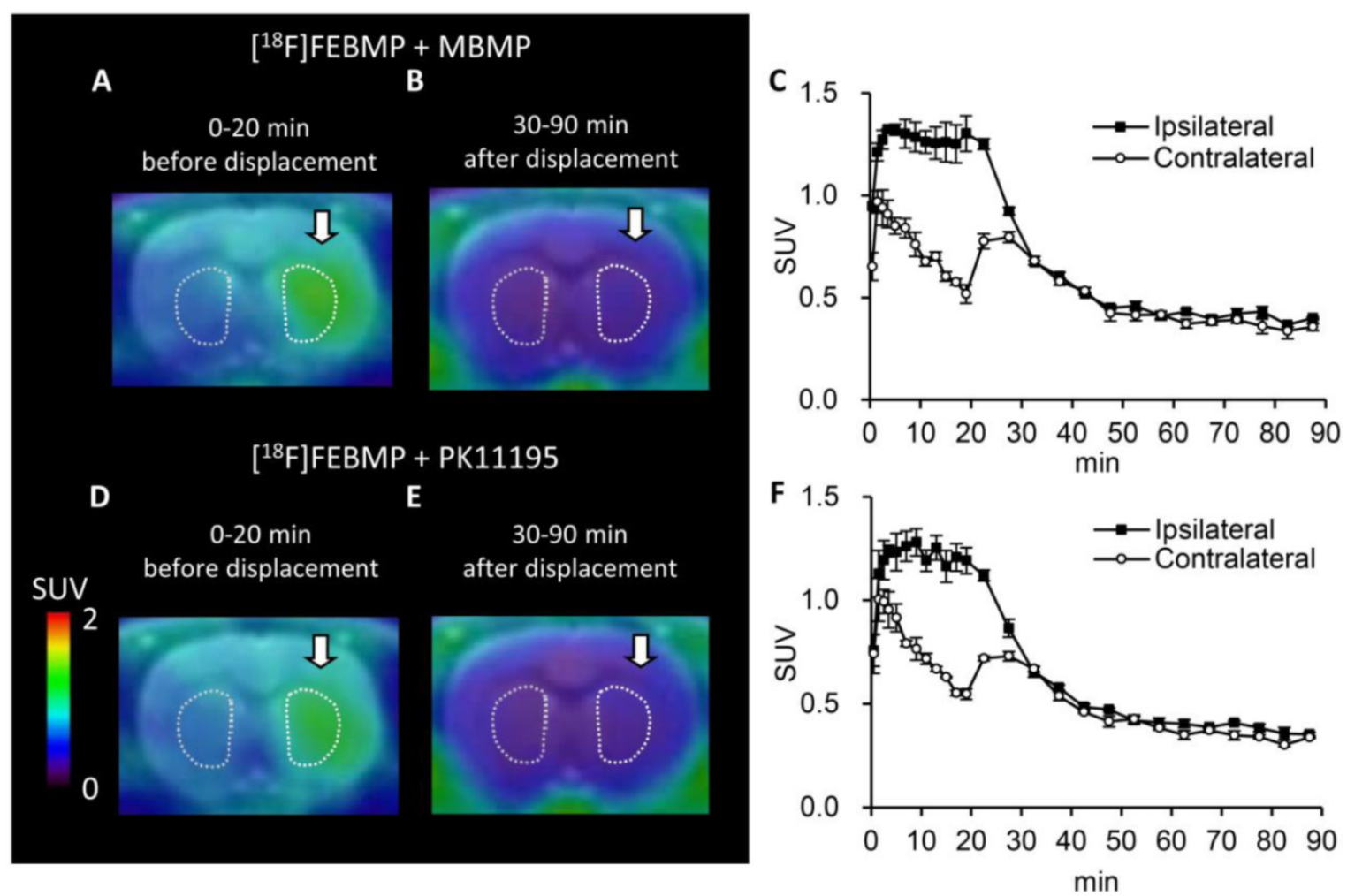

Figure 3. Displacement with unlabelled TSPO ligands for [ ${ }^{18 F}$ FEBMP uptake. A-C: Representative coronal PET summation images (A; 0-20 min, B; $30-90$ min) of $[18 \mathrm{~F}] \mathrm{FEBMP}$ and the time-activity curve $(\mathrm{C} ;$ mean $\pm \mathrm{SEM}, n=3)$ in an ischemic rat model that received additional treatment with unlabelled MBMP at 20 min after [18F]FEBMP bolus injection. D-F: Representative coronal PET summation images (D; 0-20 min, E; 30-90 min) of [18F]FEBMP and the time-activity curve (F; mean \pm SEM, $n=3)$ in a rat model of ischemia. The rat received additional treatment with unlabelled PK11195 at 20 min after [18F]FEBMP bolus injection. Ipsilateral and contralateral indicate ipsilateral and contralateral sides of the ischemic brain in the striatum. 


\section{Analysis of radiolabelled metabolites}

In order to evaluate the metabolic stability of $\left[{ }^{18} \mathrm{~F}\right]$ FEBMP, we analyzed radioactive metabolites in plasma and brain samples collected at 30 and $60 \mathrm{~min}$ post-injection (Table 2). In plasma and brain tissue, in addition to the peak of intact $\left[{ }^{18} \mathrm{~F}\right]$ FEBMP (retention time $\left.\left(t_{R}\right)=4.1 \mathrm{~min}\right)$, only one radioactive peak $\left(t_{R}=\right.$ $2.1 \mathrm{~min}$ ) was detectable on the radio-HPLC, The percentage of intact $\left[{ }^{18} \mathrm{~F}\right] \mathrm{FEBMP}$ in the plasma decreased to $8.6 \pm 1.9 \%$ and $3.9 \pm 1.1 \%$ at $30 \mathrm{~min}$ and $60 \mathrm{~min}$ after injection, respectively. Meanwhile, intact $\left.{ }^{18} \mathrm{~F}\right]$ FEBMP in the brain remained at $83.1 \pm 7.3 \%$ and $76.4 \pm 2.1 \%$ at 30 and 60 min post-injection, respectively. The radioactivity recovery rate from the HPLC analysis for all samples was $>95 \%$.
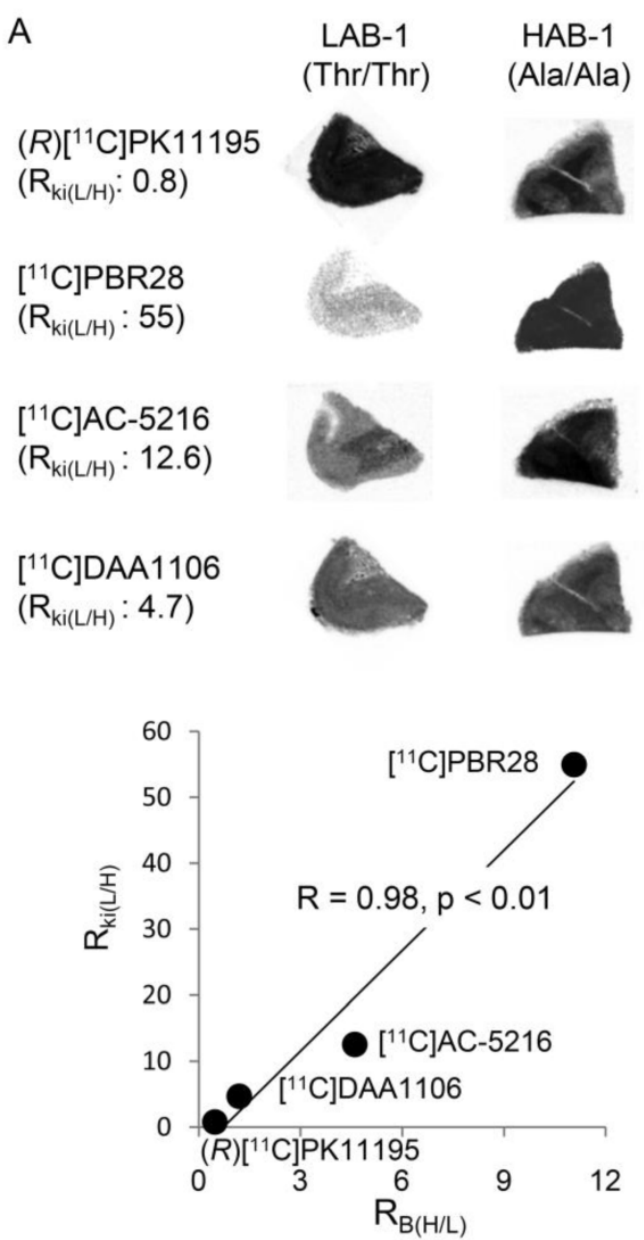

Figure 4. In vitro autoradiographic analysis of the human brain. (A) Autoradiographic images of (R)["IC]PK11195, ["IC]PBR28, ["IC]AC-5216, and ["IC]DAA1106 in brain sections containing the temporal cortex from LAB-1 and HAB-1. The binding ratios of $(R)$ ["IC]PK11195, ["IC]DAA1106, ["IC]AC-5216 and ["IC]PBR28 for HAB-1 to that of $L A B-1\left(R_{B(H / L)}\right)$ were approximately $0.45,1.19,4.60$, and 11.1, respectively, showing excellent correlation $(R=0.98, p<0.01)$ with the Ki ratios of these ligands for $L A B$ to that of $H A B\left(R_{K_{i}(H / L)}\right)$. The corresponding values of $R_{K_{i}(H / L)}$ of these lignads were $0.8,4.7,12.6$ and 55 , respectively, published in previous studies (Owen et al, $201 \mathrm{la}, 201 \mathrm{lb}$ ). (B) Autoradiographic images of [18F]FEBMP and quantitative analysis. Total binding (TB, PSL/mm²; mean \pm SEM) and non-specific binding (NSB, PSL/mm²; mean \pm SEM) were calculated in the absence and presence of unlabeled PK11195, respectively ( 3 and 5 brain sections for the NSB and TB assay, respectively; $*, p<0.05,{ }^{* *}, p<0.01$; student's $t$-test for TB vs NSB). The $R_{B(L H)}$ value of [ ${ }^{18}$ F]FEBMP was determined to be 0.90 from the bar graph. $*$ The $R_{k i}(L H)$

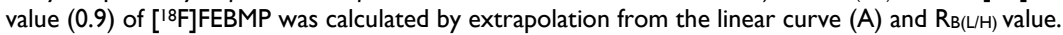

Table 2. Metabolite analysis of $\left[{ }^{18} \mathrm{~F}\right] \mathrm{FEBMP}$ in ischemic rats

\begin{tabular}{lllll}
\hline Time $(\mathrm{min})$ & \multicolumn{2}{c}{$\%$ in plasma } & \multicolumn{2}{c}{$\%$ in brain } \\
\cline { 2 - 5 } & Metabolite & Parent & Metabolite & Parent \\
\hline 30 & $91.4 \pm 1.9$ & $8.6 \pm 1.9$ & $16.8 \pm 7.4$ & $83.2 \pm 7.4$ \\
60 & $96.1 \pm 1.1$ & $3.9 \pm 1.1$ & $23.6 \pm 2.1$ & $76.4 \pm 2.1$ \\
\hline
\end{tabular}

Data are presented as Mean \pm SEM.

In vitro autoradiography

Autoradiographic analyses with (R)[11C]PK11195, [ $\left.{ }^{11} \mathrm{C}\right]$ PBR28, [ $\left.{ }^{11} \mathrm{C}\right] \mathrm{AC}-5216$, and [11C]DAA1106 showed that there were overtly different binding sites for these radioligands between two postmortem human brains, LAB-1 and HAB-1 (Fig. 4). In vitro binding of $(R)\left[{ }^{11} \mathrm{C}\right] \mathrm{PK} 11195$ was a little higher in LAB-1 than in HAB-1. On the other hand, compared to $(R)\left[{ }^{11} \mathrm{C}\right] \mathrm{PK} 11195$, in vitro binding of [11C]PBR28 was greatly lower in LAB-1. The binding in LAB-1 was also lower than in HAB-1 (Fig. 4A).

B

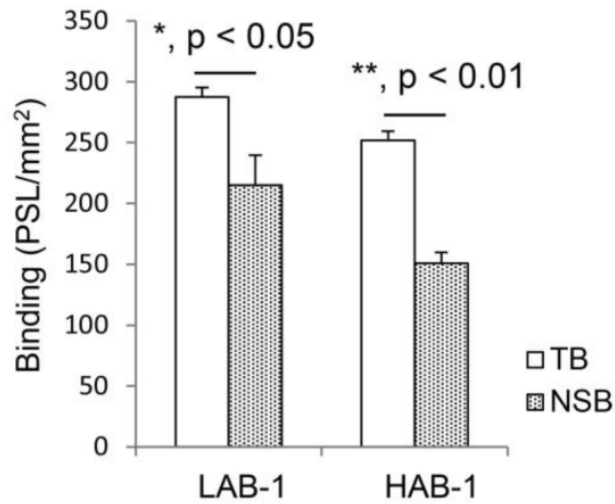

\section{$\left[{ }^{18} \mathrm{~F}\right] \mathrm{FEBMP}$}

$\left({ }^{\star} R_{\text {ki(L/H) })}: 0.9\right)$
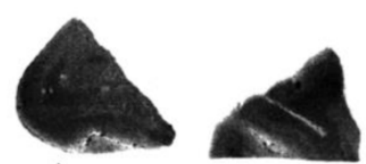

$\left[{ }^{18} \mathrm{~F}\right] \mathrm{FEBMP}$

$+$

PK11195

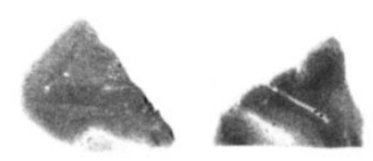


This result was completely consistent with widely accepted consideration that amino acid substitution from alanine to threonine leads to low-affinity binding for $\left.{ }^{[11} \mathrm{C}\right] \mathrm{PBR} 28$ while not affecting the binding affinity of $(R)\left[{ }^{11} \mathrm{C}\right] \mathrm{PK} 11195$ [19]. Autoradiography with $\left[{ }^{11} \mathrm{C}\right] \mathrm{AC}-5216$ and $\left[{ }^{11} \mathrm{C}\right] \mathrm{DAA} 1106$ also showed decreased binding in LAB-1 compared to $(R)\left[{ }^{11} \mathrm{C}\right] \mathrm{PK} 11195$, and this is also consistent with previous publications $[19,20]$. Moreover, there was an excellent correlation $(R=0.98, p<0.01)$ between the ratio of binding of TSPO ligands for HAB-1 to LAB-1 $\left(\mathrm{R}_{\mathrm{B}(\mathrm{L} / \mathrm{H})}\right)$ and the ratio of $\mathrm{K}_{\mathrm{i}}$ for $\mathrm{LAB}$ to $\mathrm{HAB}\left(\mathrm{R}_{\mathrm{Ki}(\mathrm{L} / \mathrm{H})}\right)$ of these ligands published in previous studies $[19,20]$ (Fig. 4A). The presence of unlabelled PK11195 caused a moderate but significant decrease in the binding of $\left[{ }^{18} \mathrm{~F}\right] \mathrm{FEBMP}$ in both human brains, and the $\mathrm{R}_{\mathrm{Ki}(\mathrm{L} / \mathrm{H})}$ value of $\left[{ }^{18} \mathrm{~F}\right] \mathrm{FEBMP}$ was estimated to be 0.9 , which was calculated by extrapolation from the linear curve (Fig. 4A) and its $\mathrm{R}_{\mathrm{B}(\mathrm{L} / \mathrm{H})}$ value of 0.90 determined from the bar graph in Fig. 4B, suggesting that binding of $\left[{ }^{18} \mathrm{~F}\right]$ FEBMP was little affected by TSPO rs6971 polymorphism. This result was also supported by quantitative analysis including two HAB and two LABs. The amount of specific binding of [ $\left.{ }^{18} \mathrm{~F}\right] \mathrm{FEBMP}$ in $\mathrm{HAB}$ and LAB groups was similar, in contrast with approximately 21-fold difference in specific binding of $\left[{ }^{11} \mathrm{C}\right]$ PBR28 between HAB and LAB groups (Supplementary Material: Figure S1).

\section{Discussion}

In the current study, we developed a new PET radioligand, $\left.{ }^{18} \mathrm{~F}\right] \mathrm{FEBMP}$, that could prove useful for the imaging of neuroinflammation. [ $\left.{ }^{18} \mathrm{~F}\right] \mathrm{FEBMP}$ showed high binding affinity $\left(\mathrm{K}_{\mathrm{i}}=6.6 \mathrm{nM}\right)$ for TSPO and suitable lipophilicity $(\log D=3.43)$ for brain permeability [23]. Moreover, PET images with $\left[{ }^{18} \mathrm{~F}\right]$ FEBMP were able to capture TSPO induction in a rat model of focal cerebral ischemia. In vitro autoradiographic analysis in post-mortem brains from $\mathrm{LAB}$ and HAB tissues implied little influence of the TSPO rs6971 polymorphism on the [ $\left.{ }^{18} \mathrm{~F}\right] \mathrm{FEBMP}$ binding site.

Biodistribution in mice showed that the radioactivity rapidly accumulated in TSPO-rich tissues, such as the lungs, heart, and kidneys. This finding was in agreement with previous studies on TSPO localization in the peripheral systems of animals and humans [28]. Moreover, this was similar to the distribution profiles that had independently emerged from the chemical class of the radioligands $\left[{ }^{11} \mathrm{C}\right] \mathrm{PK} 11195,\left[{ }^{11} \mathrm{C}\right] \mathrm{DAA} 1106$, and [18F]FEDAA1106, which peaked early (1 to $10 \mathrm{~min}$ ) after injection [13]. As expected from its lipophilicity, $\left[{ }^{18} \mathrm{~F}\right]$ FEBMP showed excellent brain permeability with an initial uptake of approximately $2.7 \% \mathrm{ID} / \mathrm{g}$ in normal mouse brains. Furthermore, radioactivity uptake in the bones of mice reached up to
$3.8 \pm 0.1 \% \mathrm{ID} / \mathrm{g}$ at $90 \mathrm{~min}$. It is not a negligible value, PET images of the ischemic rat brain, however, showed no obvious accumulation of radioactivity in the skull. This seemingly contradictory finding may be explainable because the thighbone samples we collected contained abundant marrow where there was detectable expression of TSPO [29]. Thus, accumulated radioactivity in bone samples may be mainly due to $\left[{ }^{18} \mathrm{~F}\right]$ FEBMP binding to marrow, and not free $\left[{ }^{18} \mathrm{~F}\right] \mathrm{F}-$ trapped in bones.

Because of the low TSPO expression in normal brains, we used a rat model of focal cerebral ischemia in order to overtly induce TSPO expression in the ipsilateral striatum without widespread disruption and breakdown in function of the blood-brain barrier [25]. This allowed us to verify the feasibility of $\left.{ }^{[18} \mathrm{F}\right]$ FEBMP for detecting neuroinflammation. Using this approach, we observed more binding sites on the ischemic side of the brain when compared to the corresponding contralateral area [22, 23]. In the present study, after the infusion of unlabeled MBMP or PK11195, there was an overt increase in the contralateral but slight change in ipsilateral side. Given that the increased blood concentration of radioligand, due to replacement in peripheral tissues, competitive inhibition of metabolism, or excretion, usually causes temporary increase in radioactivity level in the brain region with poor binding sites for the radioligand. In brain region with abundant binding sites, reduced specific binding at the same time would mask and even cancel this change. This result also indirectly suggested that there was less specific binding in contralateral area, compared to ipsilateral side. Thus, we were able to generate an apparent $\mathrm{BP}_{\mathrm{ND}}$ of $\left[{ }^{18} \mathrm{~F}\right] \mathrm{FEBMP}$ with SRTM, using the contralateral area as a reference tissue. Although this apparent $\mathrm{BP}_{\mathrm{ND}}$ is an underestimated value since there is specific binding due to existence of ramified, or slightly activated microglia in the reference tissue, such influence might be acceptable. Moreover, utilization of this apparent $\mathrm{BP}_{\mathrm{ND}}$ allowed us to compare the present data with our previously published data. The apparent $\mathrm{BP}_{\mathrm{ND}}$ of $\left[{ }^{18} \mathrm{~F}\right]$ FEBMP was $2.72 \pm 0.27$ in the present study, which was significantly higher than the that of [11C]MBMP $(2.03 \pm 0.24, p<0.05)$ and $(R)\left[{ }^{11} \mathrm{C}\right] \mathrm{PK} 11195$ $(1.59 \pm 0.33, p<0.05)$ [22], strongly suggesting the superiority of $\left[{ }^{18} \mathrm{~F}\right] \mathrm{FEBMP}$ in detecting TSPO in living individuals. A rather high level of non-specific binding was detected in the postmortem brain, possibly due to low level of TSPO expression in healthy control brain. Such low-level binding may be beneficial for detecting activated microglia in inflamed human brain as seen in the present ischemic rat model.

In the current study, we determined that the metabolic stability of [18$\left.{ }^{18} \mathrm{~F}\right]$ FEBMP was not desirable 
since its radiolabelled metabolite was observed to increase rapidly to more than $90 \%$ in plasma within 30 min. Furthermore, the metabolite was also found in brain tissue. The PET images with $\left.{ }^{18}{ }^{18} \mathrm{~F}\right] \mathrm{FEBMP}$, however; still showed clear visualization of neuroinflammation in the rat model of focal ischemia. Therefore, the assessment of TSPO with [18F]FEBMP might not be greatly disturbed by the radioactivity (approximately $20 \%$ ) due to the metabolite in the brain. It is still unclear that the radiolabelled metabolite also had affinity for TSPO. Metabolism is often different between experimental animals and humans, thus, PET imaging in human brains may show greatly different features than the findings reported here. Further investigation on human subjects is being contemplated in a collaborative study with our clinical department.

Amino acid substitution from alanine to threonine in TSPO rs6971 polymorphism leads to a conversion from $\mathrm{HAB}$ to $\mathrm{LAB}$ for many second-generation TSPO ligands. Here, we established a method using a binding value from a single concentration of $\left[{ }^{11} \mathrm{C}\right]$ FEBMP instead of the Ki value from a range of the concentrations being tested. The latter is a common method that is used for examining the influence of the TSPO polymorphism on TPSO ligand binding sites $[19,20]$. Correlation analysis for various TSPO ligand binding to one HAB and one LAB brain found an excellent correlation between $\mathrm{R}_{\mathrm{B}(\mathrm{H} / \mathrm{L})}$ and the published $\mathrm{R}_{\mathrm{Ki}(\mathrm{L} / \mathrm{H})}$ values (Fig. $\left.4 \mathrm{~A}\right)$, suggesting the validity of our method. Furthermore, the $\mathrm{R}_{\mathrm{Ki}(\mathrm{L} / \mathrm{H})}$ value of $\left[{ }^{18} \mathrm{~F}\right]$ FEBMP was approximately 0.9 , while the $\mathrm{R}_{\mathrm{Ki}(\mathrm{L} / \mathrm{H})}$ values of $(R)\left[{ }^{11} \mathrm{C}\right] \mathrm{PK} 11195$ and $\left[{ }^{11} \mathrm{C}\right] \mathrm{PBR} 28$ have been published as 0.8 and 55, respectively [19]. These data convincingly demonstrate that $\left[{ }^{18} \mathrm{~F}\right] \mathrm{FEBMP}$ is a promising second-generation TSPO ligand, and that the TPSO polymorphism has little influence on its binding affinity. Further examination using amplified sample size also support this consideration (Supplementary Material: Figure S1). It is still unclear what chemical structure is critical for LAB binding. In fact, even a slight modification in the side chain might greatly affect the binding affinity for LAB. For example, although they are phenoxyphenylacetamide derivatives, the $\mathrm{R}_{\mathrm{Ki}(\mathrm{L} / \mathrm{H})}$ of $\left[{ }^{11} \mathrm{C}\right] \mathrm{PBR} 28,\left[{ }^{18} \mathrm{~F}\right] \mathrm{PBR} 06$, and $\left.{ }^{11} \mathrm{C}\right] \mathrm{DAA} 1106$ is greatly different at 55,17 , and 4.7 , respectively [19]. However, given that the prevalence of Thr147 (low-binding allele) is 30\% in Caucasians and $25 \%$ in Africans [21], [ $\left.{ }^{18} \mathrm{~F}\right]$ FEBMP could prove as a general utility for the sensitive detection of neuroinflammation. Furthermore, $\left[{ }^{18} \mathrm{~F}\right]$ FEBMP could serve as a core chemical structure for new PET ligands and anxiolytics in the entire population, including in individuals with TSPO rs6971 polymorphisms.

\section{Supplementary Material}

Figures S1. http:/ / www.thno.org/v05p0961s1.pdf

\section{Abbreviations}

$\mathrm{BP}_{\mathrm{ND}}$ binding potential; [11C]MBMP, 2-[5-(4-[11C]methoxy-2-oxo-1,3-benzoxazol-3(2H)-yl)$N$-methyl-N-phenylacetamide; FEBMP, 2-[5-(4-fluoroethoxy-2-oxo-1,3-benzoxazol-3(2H)-yl)-N-methyl$N$-phenylacetamide; $\quad\left[{ }^{18} \mathrm{~F}\right] \mathrm{FEBMP}, \quad 2-\left[5-\left(4-\left[{ }^{18} \mathrm{~F}\right]\right.\right.$ fluoroethoxy-2-oxo-1,3-benzoxazol-3(2H)-yl)-N-methyl$N$-phenylacetamide; HAB, high-affinity binder; \% $\mathrm{ID} / \mathrm{g}$, percentage of the injected dose per gram of wet tissue; Ki, binding affinity; LAB, low-affinity binder; $\mathrm{MAB}$, mixed-affinity binder; MBMP, 2-[5-(4-methoxy-2-oxo-1,3-benzoxazol-3(2H)-yl)-N-me thyl-N-phenylacetamide; MRI, magnetic resonance imaging; PET, positron emission tomography; SRTM, simplified reference tissue model; SD, Sprague-Dawley; SUV, standardized uptake value; TAC, time-activity curve; TSPO, translocator protein (18 $\mathrm{kDa})$.

\section{Acknowledgements}

The authors would like to thank the staff at the National Institute of Radiological Sciences for their support with the cyclotron operation, radioisotope production, radiosynthesis, and animal experiments. The first author would also like to thank the Japan Society for the Promotion of Science for financial support.

\section{Competing Interests}

All experiments were conducted in compliance with the ARRIVE guidelines. The authors have declared that no competing interest exists.

\section{References}

1. Papadopoulos V, Baraldi M, Guilarte TR, et al. Translocator protein (18 kDa): new nomenclature for the peripheral-type benzodiazepine receptor based on its structure and molecular function. Trends Pharmacol Sci. 2006; 27: 402-9.

2. Chen MK, Guilarte TR. (2008) Translocator protein $18 \mathrm{kDa}$ (TSPO): molecular sensor of brain injury and repair. Pharmacol Ther. 2008; 118: 1-17.

3. Lavisse S, Guillermier M, Hérard AS, et al. (2012) Reactive astrocytes overexpress TSPO and are detected by TSPO positron emission tomography imaging. J Neurosci. 2012; 32: 10809-18.

4. Camsonne R, Crouzel C, Comar D, et al. Synthesis of $\mathrm{N}-\left[{ }^{11} \mathrm{C}\right]-$ methyl, $\mathrm{N}$-(methyl-1-propyl), (chloro-2-phenyl)-1-isoquinoline carboxamide-3 (PK11195): a new ligand for peripheral benzodiazepine receptors. J. Labelled Comp Radiopharm. 1984; 21: 985-91.

5. Chauveau F, Boutin H, Van Camp N, et al. Nuclear imaging of neuroinflammation: a comprehensive review of $\left[{ }^{11} \mathrm{C}\right] \mathrm{PK} 11195$ challengers. Eur J Nucl Med Mol Imaging. 2008; 35: 2304-19.

6. Kropholler MA, Boellaard $\mathrm{R}$, Elzinga $\mathrm{EH}$, et al. Quantification of $(R)-\left[{ }^{11} \mathrm{C}\right]$ PK11195 binding in rheumatoid arthritis. Eur J Nucl Med Mol Imaging. 2009; 36: 624-31.

7. Lamare F, Hinz R, Gaemperli $\mathrm{O}$, et al. Detection and quantification of large-vessel inflammation with ${ }^{11} \mathrm{C}-(R)-\mathrm{PK} 11195$ PET/CT. J Nucl Med. 2001; 52: 33-9.

8. Kreisl WC, Lyoo $\mathrm{CH}$, McGwier M, et al. In vivo radioligand binding to translocator protein correlates with severity of Alzheimer's disease. Brain. 2013; 136: 2228-38.

9. Dollé F, Luus C, Reynolds A, et al. Radiolabelled molecules for imaging the translocator protein $(18 \mathrm{kDa})$ using positron emission tomography. Curr Med Chem. 2009; 16: 2899-923. 
10. Trapani A, Palazzo C, de Candia M, et al. Targeting of the translocator protein $18 \mathrm{kDa}$ (TSPO): a valuable approach for nuclear and optical imaging of activated microglia. Bioconjug Chem. 2014; 24: 1415-28.

11. Zhang MR, Kida T, Noguchi J, et al. [11C]DAA1106: radiosynthesis and in vivo binding to peripheral benzodiazepine receptors in mouse brain. Nucl Med Biol. 2003; 30: 513-9.

12. Yasuno F, Kosaka J, Ota M., et al. Increased binding of peripheral benzodiazepine receptor in mild cognitive impairment-dementia converters measured by positron emission tomography with $\left[{ }^{11} \mathrm{C}\right] \mathrm{DAA} 1106$. Psychiatry Res. 2021; 203: 67-74.

13. Zhang MR, Maeda J, Ogawa M, et al. Development of a new radioligand, $\mathrm{N}$-(5-fluoro-2-phenoxyphenyl)-N-(2-[ $\left.{ }^{18} \mathrm{~F}\right]$ fluoroethyl-5-methoxybenzyl)acetam ide, for PET imaging of peripheral benzodiazepine receptor in primate brain. J Med Chem. 2004; 47: 2228-35.

14. Takano A, Piehl F, Hillert J, et al. In vivo TSPO imaging in patients with multiple sclerosis: a brain PET study with $\left[{ }^{18} \mathrm{~F}\right]$ FEDAA1106. EJNMMI Res. 2013; 3: 30-3.

15. Brown AK, Fujita M, Fujimura $Y$, et al. Radiation dosimetry and biodistribution in monkey and man of ${ }^{11} \mathrm{C}-\mathrm{PBR} 28$ : a PET radioligand to image inflammation. J Nucl Med. 2007; 48: 2072-79.

16. Zhang MR, Kumata K, Maeda J, et al. ${ }^{11} \mathrm{C}-\mathrm{AC}-5216$ : a novel positron emission tomography ligand for peripheral-type benzodiazepine receptors in primate brain. J Nucl Med. 2007; 48: 1853-61.

17. Corcia P, Tauber C, Vercoullie J, et al. Molecular imaging of microglial activation in amyotrophic lateral sclerosis. PLoS ONE. 2012; 7: e52941.

18. Fookes CJ, Pham TQ, Mattner F, et al. Synthesis and biological evaluation of substituted [18F]imidazo[1,2-a]pyridines and [ $\left.{ }^{18} \mathrm{~F}\right]$ pyrazolo[1,5-a]pyrimidines for the study of the peripheral benzodiazepine receptor using positron emission tomography. J Med Chem. 2008; 51: 3700-12.

19. Owen DR, Gunn RN, Rabiner EA, et al. Mixed affinity binding in humans with 18-kDa translocator protein ligands. J Nucl Med. 2011; 52: 24-32.

20. Owen DR, Lewis AJ, Reynolds R, et al. Variation in binding affinity of the novel anxiolytic XBD173 for the $18 \mathrm{kDa}$ translocator protein in human brain. Synapse. 2011; 65: 257-9.

21. Owen DR, Yeo AJ, Gunn RN, et al. An 18-kDa translocator protein (TSPO) polymorphism explains differences in binding affinity of the PET radioligand PBR28. J Cereb Blood Flow Metab. 2012; 32: 1-5.

22. Tiwari AK, Fujinaga $M$, Kumata $K$, et al. Characterization of a novel acetamidobenzoxazolone-based PET ligand for translocator protein $(18 \mathrm{kDa})$ imaging of neuroinflammation in the brain. J Neurochem. 2014; 129: 712-20.

23. Tiwari AK, Fujinaga $M$, Yui $J$, et al. Synthesis and evaluation of new ${ }_{18}^{18}$-labelled acetamidobenzoxazolone-based radioligands for imaging of translocator protein (18 kDa, TSPO) in brain. Org Biomol Chem. 2014, 12: 9621-30.

24. Briard E, Zoghbi SS, Imaizumi M, et al. Synthesis and evaluation in monkey of two sensitive ${ }^{11} \mathrm{C}$-labeled aryloxyanilide ligands for imaging brain peripheral benzodiazepine receptors in vivo. J Med Chem. 2008; 51: 17-30.

25. Yui J, Hatori A, Kawamura $K$, et al. Visualization of early infarction in rat brain after ischemia using a translocator protein $(18 \mathrm{kDa})$ PET ligand $\left[{ }^{11} \mathrm{C}\right] \mathrm{DAC}$ with ultra-high specific activity. NeuroImage. 2011; 54: 123-30.

26. Yui J, Maeda J, Kumata K, et al. ${ }^{18}$ F-FEAC and ${ }^{18}$ F-FEDAC: PET of the monkey brain and imaging of translocator protein $(18 \mathrm{kDa})$ in the infarcted rat brain. J Nucl Med. 2010; 51: 1301-9.

27. Lammertsma AA, Hume SP. Simplified reference tissue model for PET receptor studies. Neuroimage 1996; 4: 153-8.

28. Roivainen $\mathrm{A}$, Någren $\mathrm{K}$, Hirvonen $\mathrm{J}$, et al. Whole-body distribution and metabolism of [N-methyl-11C] R)-1-(2-chlorophenyl)-N-(1-methylpropyl)3 -isoquinolinecarboxamide in humans; an imaging agent for in vivo assessment of peripheral benzodiazepine receptor activity with positron emission tomography. Eur J Nucl Med Mol Imaging. 2009; 36:671-82.

29. Kam WW, Meikle SR, Dunstan CR, et al. The $18 \mathrm{kDa}$ translocator protein (peripheral benzodiazepine receptor) expression in the bone of normal, osteoprotegerin or low calcium diet treated mice. PLoS ONE 2012; 7: e30623. 